\title{
Research on Anechoic Chamber Using Counter-phase Counteract and Rushing
}

\author{
Shao Ying-li ${ }^{1,}$ a * \\ ${ }^{1}$ Department of Statistics and Mathematics, Inner Mongolia Finance and Economics \\ university,010070,Huhhot, P. R. China \\ ayinglishao@163.com
}

Keywords: Exhaust muffler; Backpressure; Insersion loss.

Abstract. A conventional muffler of internal combustion engine is mostly constructed as a mixture or combination of perforated ducts, baffle or perforated baffle, expansion chamber, etc., and the noise reduction is limited and backpressure is high hence the fuel efficiency is low. In order to solve the problems of traditional exhaust silencers with poor characteristics of noise reduction in low-frequency range and high exhaust resistance, a new theory of exhaust silencer of diesel engine based on counter-phase counteract and split-gas rushing has been proposed. Taking the single-cylinder diesel engine CG25 as the experimental engine, the author measured the exhaust noise and its spectra. By comparing the results of the new types of mufflers to those without a muffler and those with the original muffler of the engine, the new theory of muffler has been verified.

\section{Introduction}

The exhaust noise, which falls into low-frequency noise, is the dominant noise source of a diesel engines and tractors. It is a direct and effective way to reduce the exhaust noise by using an exhaust muffler. However, the traditional exhaust muffler, which are normally constructed by combination of expansion chamber, and perforated pipe or perforated board, are with high exhaust resistance, but poor noise reduction especially for the low-frequency band noise. Normally, there is a contradiction between the noise reduction and the exhaust resistance for an exhaust silencer, so it has a great significance in studying the theory or principle of the exhaust muffler with high-efficiency noise reduction and energy saving [1].

To solve the problems of conventional mufflers, various attempts have been tried with only limited success. Active muffler systems, in which usually a speaker to cancel the exhaust noise is used, have been actively researched in recent years [2.4]. However, this method has failed to be commercialized due to some problems. Various other attempts like using an U-shaped bypass pipe attached to the original exhaust pipe, using the swirl phenomenon in mufflers, have also failed in commercial application due to numerous problems inherent in their design [5].

A new theory of exhaust silencer of diesel engine based on counter-phase and split-gas rushing has been proposed. The theory is, the dominant low-frequency noise components are controlled by counteract of two sound waves with counter-phases $\left(180^{\circ}\right.$ phase difference); the other frequency-band noise is reduced by lowering the exhaust gas flow rate thus lowering exhaust noise. The exhaust resistance based on the new theory is low because of the structure without perforated pipe or perforated board where small holes are used, and the no reduction of gas-flow sections in all the way of gas flow

\section{Principle of the muffler}

The principle of the new muffler is shown in Fig.1. The exhaust gases are introduced in inlet and directed by a cone, flowing into the space between inner and outer pipes, and then distributed automatically, coming into the chambers through the radial rectangular slits using a U-shaped bypass pipe. In each chamber, the coming exhaust gases are divided into two parts which has the same magnitude and $180^{\circ}$ phase difference, when these two parts gases are made to meet at centre-line of the chamber, they are canceled each other, leading that gas flow speed is lowered. Also the expansion 
chamber in the middle of the muffler helps to reduce the noise further. Since the two openings chambers located at each chamber are big rectangular slits and also the gas flow speed is lowered by the canceling, the pressure loss is much lower when gas goes through the muffler, meaning that the backpressure of the muffler is lower.

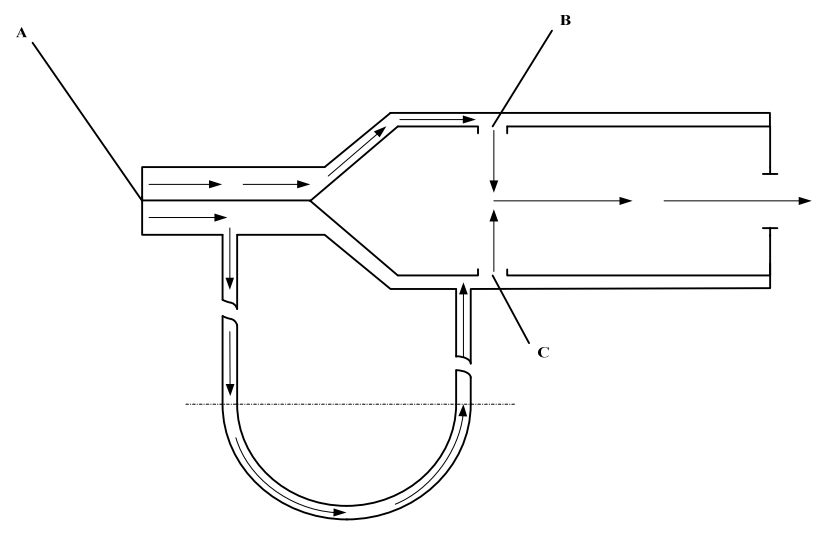

Fig. 1 Principle of the muffler using reversed-phase canceling

\section{Exhaust noise measurement experiment}

An experimental muffler based on the proposed principle was designed and fabricated for a single cylinder diesel engine, the basic specifications of the engine are given in Table 1.

Table1. Specifications of the tested engine

\begin{tabular}{l|l|l}
\hline & Items & Specifications \\
\hline 1 & Model & CG25 \\
2 & Rated revolution & $2200 \mathrm{r} / \mathrm{min}$ \\
3 & Over-load power & $16.18 \mathrm{~kW}$ \\
4 & $12 \mathrm{~h}$ power & $14.71 \mathrm{~kW}$ \\
5 & Number of cylinders & 1 \\
6 & Operating principle & Four-stroke and direct injection \\
\hline
\end{tabular}

The noise attenuation characteristic of the new muffler was measured with engine experiments, and the comparison was done with the original muffler's noise attenuation characteristic and that without muffler. The original muffler of the engine is a traditional passive muffler, which is a mixture of perforated pipe, baffle, expansion chamber and interpolated duct in construction. Fig. 2 to 4 represents the sound pressure level of the exhaust noise in three cases, with new, original and without muffler.

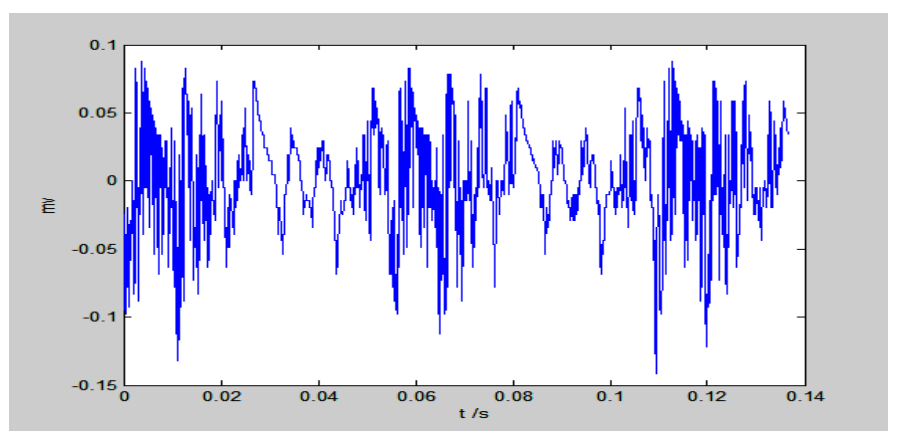

Fig. 2 The time domain chart of the new muffler at 2200r/min 


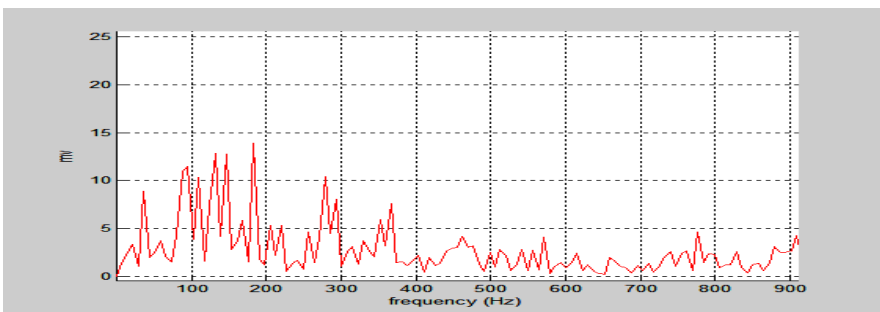

Fig.3 The spectrum of the new muffler at 2200r/min

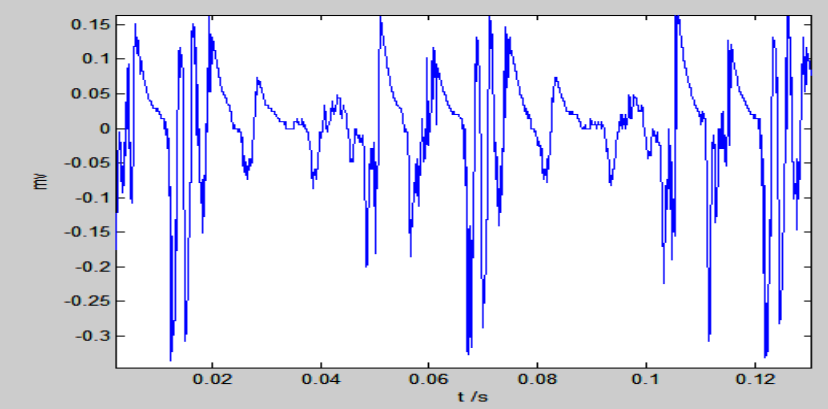

Fig.4The time domain chart of the original muffler at 2200r/min

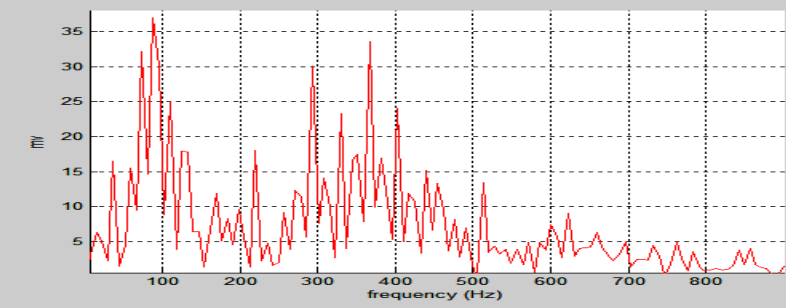

Fig.5The spectrum of the original muffler at 2200r/min

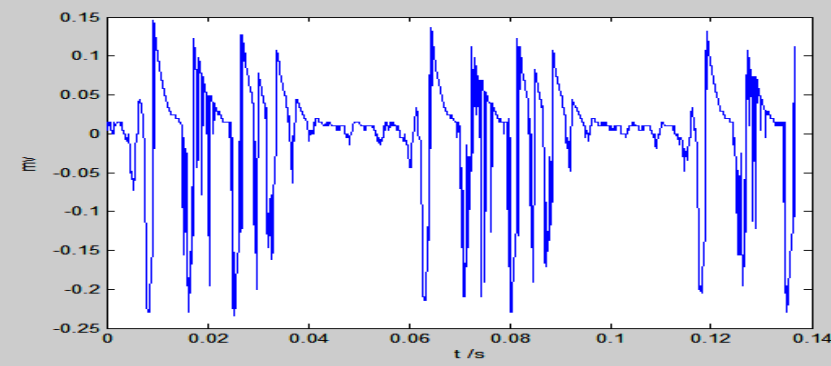

Fig.6The time domain chart of the blank pipe at 2200r/min

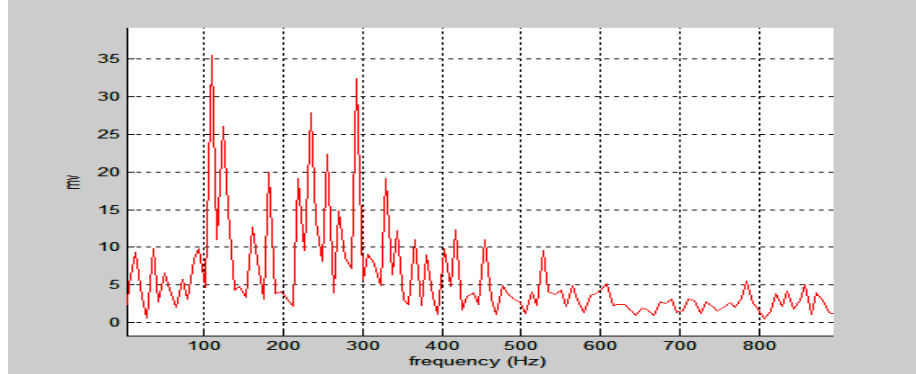

Fig.7 The spectrum of the blank pipe at 2200r/min

The observations show that the newly developed muffler has a better noise attenuation property compared to that of the original passive muffler. Considering that the measurement provides only qualitative result for comparison purpose, the unit for z-axis in these Figures is taken as voltage instead of $\mathrm{Pa}(\mathrm{dB})$. In Fig.3, it is shown that the original engine noise has a wideband noise mainly between 200 and $500 \mathrm{~Hz}$. Compared to the performance of the passive muffler the new muffler shows superior noise reduction performance. 


\section{Summary}

A new concept of exhaust muffler is proposed. The noise experiment conducted on the CG25 single cylinder diesel engine shows new muffler's good insertion loss characteristic in the wide range of engine speed comparable to the original passive muffler especially in the range of $500 \mathrm{~Hz}$. The original muffler can only reduce the high-frequency noise components, it cannot reduce, even strengthen the noise of frequency below $500 \mathrm{~Hz}$, proved conventional muffler with poor capacity of lowering the low-frequency noise again. The new exhaust mufflers were obviously effective in controlling the low-frequency exhaust noise, which proved correctness of the new theory not only proved that the new mufflers have very good performance for low-frequency noise reduction, but also proved that using split-gas rushing can lower the air flow speed thus lowering the air-regeneration noise. The counter-phase is only effective to the exhaust noise of the target frequency and its odd multiple harmonics instead of the whole frequency range, but the split-gas rushing is working to the noise in all frequency range.

\section{Acknowledgment}

This work has been supported by Inner Mongolia Natural Science Foundation of China No. 2012 MS0602.

\section{References}

[1] Mara Cuesta,Pedro Cobo:Active Control of the Exhaust Noise Radiated by an Enclosed Generator [J]. Applied Acoustics,2000(61),p.83-94.

[2] Huang Lixi.A:theoretical study of duct noise control by flexible pane[J]. JASA,1999,106(4),p.1801-1809.

[3] Zhaoyu huang,Weikang Jiang:Analysis of source models for two-dimensional acoustic systems using the transfer matrix method[J].Journal of Sound and Vibration,2007,306(1-2),p.215-226.

[4] Bilawchuk,K.R.Fyfe:Comparison and implementation of the various numerical methods used for calculating transmission loss in silencer systems.Applied Acoustic,2003,64(9),p.903-91

[5] Huang Lixi:Modal analysis of a drum silencer[J].JASA,200,112(5),p.2014-2025. 